\title{
The polymorphism of the serotonin-2A receptor T102C is associated with age
}

\author{
P.F.C. Jobim ${ }^{1}$, P.A.S. Prado-Lima², C.H.A. Schwanke ${ }^{3}$, R. Giugliani ${ }^{4}$ and I.B.M. Cruz ${ }^{5}$ \\ ${ }^{1}$ Programa de Pós-graduação em Ciências Médicas, Faculdade de Medicina, Universidade Federal do \\ Rio Grande do Sul, Porto Alegre, RS, Brasil \\ ${ }^{2}$ Instituto de Pesquisas Biomédicas, Hospital São Lucas, ${ }^{3}$ Departamento de Ciências Morfofisiológicas, \\ Faculdade de Biociências, Pontifícia Universidade Católica do Rio Grande do Sul, Porto Alegre, RS, \\ Brasil \\ 4Serviço de Genética Médica, Hospital de Clínicas de Porto Alegre, Universidade Federal do Rio Grande \\ do Sul, Porto Alegre, RS, Brasil \\ 5Departamento de Morfologia, Centro de Ciências da Saúde, Universidade Federal de Santa Maria, \\ Santa Maria, RS, Brasil
}

Correspondence to: P.F.C. Jobim, Rua dos Andradas, 343/410, 90020-000 Porto Alegre, RS, Brasil

Fax: +55-51-3062-0352. E-mail: pjobim@uol.com.br

\begin{abstract}
Epidemiological investigations suggest that T102C polymorphism of gene 5-HT2A may be associated with mean life span because diseases and behaviors related to this polymorphism, such as schizophrenia, suicide, aggression, and addiction, may potentially shorten mean life span. A sample of 687 individuals without previous neuropsychiatric disease was genotyped and separated into 3 groups according to their gender and age: 14-45 years old, 46-64 years old and 65-100 years old. Molecular genotyping was performed using the technique of polymerase chain reaction followed by restriction fragment length polymorphism using Hpall restriction enzyme. 5-HT2A genotype frequencies were: $\mathrm{TT}=21.5 \%(148), \mathrm{CC}=16.6 \%(114)$ and TC $=61.9 \%$ (425) and allele frequencies were $T=52.5 \%$ and $C=46.5 \%$. Significant differences were found between mean age of the TT genotype carriers (60.27 \pm 12.60 years) and TC genotype carriers ( $56.80 \pm 13.18$ years) of T102C polymorphism of gene 5-HT2A $(P=0.026)$ as well as the age groups $(P=0.012)$. Carriers of genotype TT were older than the other two genotypes, whereas carriers of genotype $\mathrm{CC}$ had an intermediate age compared with TT and CC subjects. The present results demonstrate an association between T102C polymorphism of gene 5-HT2A and age. Our results suggest that T102C polymorphism of gene 5HT2A is associated with mean life span, and thus this gene becomes a possible candidate for the group of adaptive genes to meat consumption proposed in the literature. Further studies should be conducted in order to elucidate this association.
\end{abstract}

Key words: Mean life span; Serotonin; Receptor 2A; T102C polymorphism

Research supported by CNPq (\#471233/2007-2, \#311231/2006-3), CAPES (\#166/08), and Fundo de Incentivo à Pesquisa e Eventos - Hospital de Clínicas de Porto Alegre (FIPE-HCPA).

Received December 6, 2007. Accepted August 26, 2008

\section{Introduction}

The theory of antagonist pleiotropic gene suggests that evolutionary pressure has selected mutations that benefit survival at pre-reproductive ages, increasing reproductive success, even if these mutations could bring adverse consequences at post-reproductive stages and old age (1). Based on the hypothesis that most biological routes have been preserved by evolution (2), studies related to mean life span or life expectancy are important for the understanding of the aging process and longevity. In fact, progress in genome studies have indicated that genetic polymorphisms contribute to mean life span (3), since more than $25 \%$ of variations in mean longevity in humans are hereditary (4).

A hypothesis suggested by Finch and Stanford (5) has 
proposed the fixation of adaptive genes to meat consumption in the human genome throughout evolution, in which such genes would be related to life span. The authors argue that meat consumption may have played an important role during human evolution, extending the lifetime of the species. The role of the adaptive genes to meat consumption would be to reduce the harmful effects of meat ingestion, such as increased cholesterol, which is a risk factor for Alzheimer's and vascular diseases, as well as reducing the risk of infection. Ancestors of human beings were hunters and scavengers who needed to pass on the knowledge of these activities to the next generations, thus increasing post-reproductive lifetime. It was in the period of childhood and adolescence that individuals developed enough skills to hunt. The reproductive success of the species is a consequence of this cycle (5).

Genes related to reproductive success via food preference may also be related to the increase in mean life span. A study conducted by Prado-Lima and colleagues (6) showed that genotype TT of T102C polymorphism of gene $5-\mathrm{HT} 2 \mathrm{~A}$ is related to a preference for meat ingestion. Another study conducted by Herbeth and colleagues (7) found an association between polymorphism 1438G/A of gene $5-\mathrm{HT} 2 \mathrm{~A}$ and fat consumption in young individuals. These authors stress the idea that these results may help explain the role of the serotonergic system in eating behavior. Both polymorphism 1438G/A and T102C are related to a variant of disequilibrium in the promoting region of gene 5-HT2A (8).

Many epidemiological investigations describe the possible association between genotype $\mathrm{CC}$ of polymorphism of gene 5-HT2A and neuropsychiatric diseases, such as schizophrenia, psychotic symptoms in Alzheimer's patients, attention deficit and hyperactivity disorder, suicide, as well as addiction to tobacco (9-11). In contrast, many other studies show a positive association between genotype TT of T102C polymorphism of gene 5-HT2A and acute myocardial infarction, stroke, high blood pressure, and high values of platelet aggregation in healthy adults (12-15). Based on these biological characteristics and studies that demonstrate associations between T102C polymorphism of gene 5-HT2A and eating preference, addiction, and chronic diseases related to alleles $\mathrm{T}$ and $\mathrm{C}$, we asked whether this polymorphism could be associated with mean life span in humans.

\section{Material and Methods}

The present observational crossover study of a population was based on the application of questionnaires and the estimate of gene diseases as proposed by Little et al.
(16). The sample was composed of 687 individuals from two sources: 267 individuals from an epidemiological study on aging conducted in Gravataí, a city located in the metropolitan area of Greater Porto Alegre, RS, Brazil, and 420 individuals from a health spa in Gramado, a city located close to the metropolitan area of Greater Porto Alegre, RS, Brazil.

Individuals who were first or second degree relatives were excluded from the sample in order to avoid error in genetic frequencies. Ancestry of the southern region of Brazil has great ethnic variation, which is highlighted in major urban areas, such as the metropolitan region of Greater Porto Alegre, which does not present any significant ethnic isolation $(17,18)$. A study conducted by $\mathrm{Da}$ Cruz and colleagues (19) showed that the ethnic composition of the metropolitan region of Greater Porto Alegre is appropriate for the implementation of epidemiological studies on aging. Thus, we opted for considering the two sources of the sample as being one single population genetically.

T102C polymorphism of gene 5-HT2A was determined by means of extraction of lymphocyte DNA, and genotyping was performed using the technique of polymerase chain reaction (PCR) described by Warren Jr. et al. (20), with small modifications made by Tsai et al. (21). Briefly, standard PCR was carried out in a $25-\mu \mathrm{L}$ volume containing $100 \mathrm{ng}$ genomic DNA, $200 \mu \mathrm{M}$ of each dNTP, $1.5 \mathrm{mM}$ $\mathrm{MgCl}_{2}, 250 \mathrm{nM}$ of the sense (5'TGTGCTACAAGTTCT GGCTT-3') and anti-sense (5'-GTGCAGTTTTTCTCTA GGG-3'). The PCR product was digested by restriction enzyme Hpall, separated by electrophoresis, and visualized with ultraviolet light. Allele $\mathrm{T}$ was not hydrolyzed by the restriction enzyme, and appeared as a DNA band of $342 \mathrm{bp}$ on the gel. Allele C presented two DNA bands at 216 and $126 \mathrm{bp}$.

Allele and genotype frequencies were tested following Hardy-Weinberg's law. The significance of the differences of the genotype distribution between the different age groups was determined by the chi-square test. In order to compare mean ages of individuals within the three genotypes, one-way ANOVA was used, followed by the post hoc Bonferroni's test. Statistical analyses were carried out with the SPSS program version 13.0 (SPSS, Inc., USA), and $P$ values greater than 0.05 were considered to be statistically significant.

This protocol was included in a project that was submitted to and approved by the Research Ethics Committee of the Pontifícia Universidade Católica do Rio Grande do Sul, affiliated with the Conselho Nacional de Saúde (\#226/01 and \#797/2001). Furthermore, the Committee of the Universidade Federal do Rio Grande do Sul approved the use 
of the retrospective data to perform the investigation described here (\#2006632/2006). Written informed consent was obtained from all participants.

\section{Results}

The lowest and highest ages of the sample were 14 and 100 years, respectively. The gender and genotype and allele distribution of the sample are reported in Table 1. Genotype and allele frequencies were in Hardy-Weinberg equilibrium. Average ages for each genotype category are reported in Table 2. Carriers of genotype TT were older than the other two genotypes. Carriers of genotype CC had an intermediate age compared with carriers of genotypes TT and heterozygous TC, whose mean age was lower (TT vs TC; $\mathrm{P}=0.026$ for ages).

Differences in genotype distribution for the three age groups, classified to reflect the biological-reproductive characteristics of Brazilian individuals were: the reproductive group (14 to 45 years; $N=123$ ), the post-reproductive group (46 to 64 years; $N=326$ ), and an elderly group (65 to 100 years; $N=238$ ). We considered that the human reproductive peak occurs before 45 years of age and declines in subsequent years. Statistically significant differences were found between the three age groups for genotype distribution ( $P=0.017$ ). The number of carriers of genotype TT was higher in the elderly group compared with the reproductive group. The number of carriers of genotype CC was higher in the post-reproductive group compared with the other two age groups, and the number of carriers of genotype TC gradually decreased from the reproductive group to the elderly group (Figure 1). No statistically significant differences were found between gender and the distribution of genotypes.

\section{Discussion}

In the present study, we investigated the possible association between polymorphism T102C of gene 5 -HT2A and age. Statistically significant differences were found between genotype distribution and age. Carriers of genotype TT apparently live longer than carriers of the other genotypes. This association was suggested when we analyzed the 5-HT2A allele and genotype frequencies of all three groups together. These were in Hardy-Weinberg equilibrium.

There also seems to be a bottleneck effect related to genotype $\mathrm{CC}$ at post-reproductive ages, since the number of individuals with this genotype decreases in the postreproductive group but not in the elderly group. On the other hand, the number of carriers of genotype TC seems to decrease as they grow old. Moreover, the mean age of carriers of genotype TT was significantly higher than the mean age of carriers of genotype TC.

The interpretation of the results obtained herein was made from a biological-evolutionary standpoint. As a result, four main questions arise. First, considering the nullity of the migration effect, consanguineous crossing-overs, and mutation rates in the sample, why is a decrease in the number of carriers of genotype CC taking place only in the

Table 1. Characterization of subjects genotyped for serotonin$2 \mathrm{~A}$ receptor $\mathrm{T} 102 \mathrm{C}$ polymorphism.

\begin{tabular}{lc}
\hline & Number (\%) \\
\hline Gender & \\
Male & $263(38.3 \%)$ \\
Female & $424(61.7 \%)$ \\
Genotype frequency & \\
TT & $148(21.5 \%)$ \\
CC & $114(16.6 \%)$ \\
TC & $425(61.9 \%)$ \\
Allele frequency & \\
T & $721(52.5 \%)$ \\
C & $653(47.5 \%)$
\end{tabular}

Data are reported as number with percent in parentheses.

Table 2. Age of subjects with each genotype of gene 5-HT2A.

\begin{tabular}{ll}
\hline Genotypes & \multicolumn{1}{c}{ Age (years) } \\
\hline TT & $60.27 \pm 12.60^{\mathrm{a}}$ \\
CC & $58.07 \pm 15.48^{\mathrm{a}, \mathrm{b}}$ \\
TC & $56.80 \pm 13.18^{\mathrm{b}}$ \\
Total & $57.75 \pm 13.52$
\end{tabular}

Data are reported as mean \pm SD. Means with the same superscript letters did not present statistical differences using one-way ANOVA followed by the post hoc Bonferroni's test.

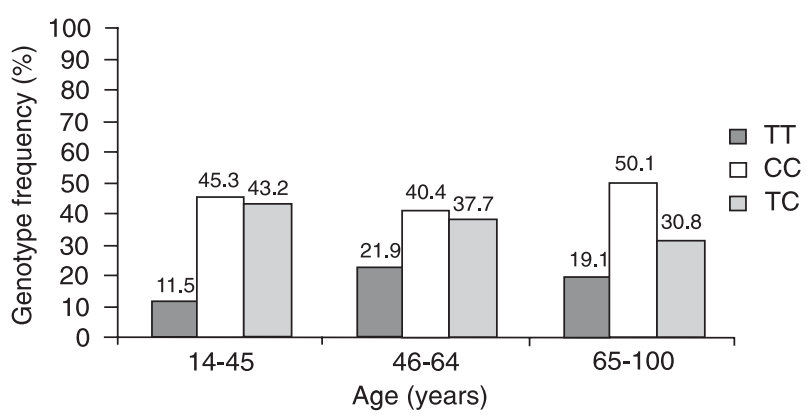

Figure 1. Distribution of the 5-HT2A genotypes by age groups. 
post-reproductive group? Second, why does the number of genotype TC carriers gradually decrease from the reproductive group to the elderly group, i.e., why do they apparently live less compared to carriers of the other genotypes? Third, why, opposite to carriers of genotype TC, do carriers of genotype TT apparently live longer compared with carriers of the other genotypes? Fourth, can the behavior of gene 5-HT2A in this study support the hypothesis that adaptive genes to meat consumption are related to mean human life span as proposed by Finch and Stanford? These questions are both complex and will hardly be answered by this investigation; however, we sought to explore some elements that may contribute to provide biologically relevant answers.

First, it is important to understand the biological role of serotonin (5-HT). 5-HT is an ancestral molecule that has recently acted as a neurotransmitter, regulating several brain functions, as well as being involved in a broad variety of behaviors, such as fear, sleep, appetite, mood, and sexual behavior (22). Deficits in the modulation of 5-HT result in many chronic non-communicable diseases, such as cardiovascular diseases and psychiatric disorders (22).

Many lines of evidence suggest that T102C polymorphism of gene 5-HT2A plays an important role in suicide, impulsiveness, and emotional alterations (23). The results of case-control studies have suggested a possible association between allele $\mathrm{C}$ of T102C 5-HT2A gene polymorphism and neuropsychiatric diseases, although the data are still controversial. Bjork et al. (24) observed that homozygous patients for allele $C$ presented increased suicidal ideation and suggest that the T102C form of gene 5HT2A may be a marker for psychiatric disorders. Studying the association between $\mathrm{T} 102 \mathrm{C}$ polymorphism of gene 5HT2A and attention deficit and hyperactivity disorder (ADHD), Li et al. (25) reported that genotype TT has a protecting role, genotype TC is a risk factor and allele $C$ is a predisposing factor for the disease in women with ADHD.

A study conducted by Choi et al. (26) suggests the association between genotype CC and low HDL levels in Koreans. Moreover, Liolitsa et al. (27) reported an increase in the frequency of allele $\mathrm{C}$ in individuals with high blood pressure. On the other hand, Yamada et al. (12) suggest that T102C polymorphism of gene 5-HT2A may be a genetic marker for acute myocardial infarction. However, probably the most explored line of research in relation to polymorphism T102C of gene 5-HT2A is schizophrenia since serotonergic metabolism is involved in the etiology of schizophrenia, a disease that affects about $1 \%$ of the world population (28). Research suggests that schizophrenia has a hereditary characteristic (29), and many studies point to a relationship between T102C polymor- phism of gene $5-\mathrm{HT} 2 \mathrm{~A}$ and this disease $(30,31)$, as well as for the therapeutic action of clozapine (32).

Unfortunately, there is very little demographic data available on mortality caused by neuropsychiatric diseases. Based on data published by the database of the Brazilian public health system (33), in the State of Rio Grande do Sul the mortality rate due to behavioral diseases (CID-10.V) is high (11/100,000 in 1999). These include mood disorders, schizophrenia, personality and emotional disorders, among other diseases that are potentially influenced by T102C polymorphism of gene 5-HT2A especially in the post-reproductive group. For this reason, complementary case-control studies between neuropsychiatry pathologies and the polymorphism studied here need to be perfomed in the Rio Grande do Sul population.

A previous study showed that in humans there is a linear loss of receptor $5-\mathrm{HT} 2 \mathrm{~A}$ of about 16 and $18 \%$ per decade of life in the hippocampus and prefrontal cortex, respectively (34). The authors report that receptor 5-HT2A decreases dramatically in many brain regions after the age of 50. Polesskaya and Sokolov (35) developed a method to determine the effect of alleles $T$ and $C$ of $T 102 C$ polymorphism of gene 5-HT2A through the expression of mRNA. Using this technique, the authors demonstrated that the expression of allele $C$ is $20 \%$ lower compared to the expression of genotype T. Two other studies $(6,11)$ that used a subject sample similar to the one used herein found that allele $\mathrm{C}$ is more frequent in individuals who smoke, and that carriers of genotype TT have a stronger preference for consuming meat compared to carriers of at least one allele $\mathrm{C}$.

Currently, little is known about genetic polymorphisms associated to mean life span. However, polymorphisms in the serotonergic system change neurometabolic routes, leading to neuropsychiatric diseases and behaviors that potentially lead to death or to conditions that shorten life expectancy.

Other more recent studies support this hypothesis. For instance, the investigation conducted by Gondo and colleagues (36) compared centennial and young individuals and suggests an association between the serotonin transporter gene (5-HTT) and longevity via negative predictors of longevity. On the other hand, Stessman et al. (37) did not find an association between the same polymorphism of 5-HTT and longevity in Jewish individuals who live in Jerusalem, which suggests the occurrence of intervening variables, which may include the interaction between genetic polymorphisms influencing longevity. In the present study, we worked only with the part related to the effect of a single nucleotide polymorphism (SNP); however, it should be possible to systematize environmental influences such 
as negative and positive predictors of mean life span.

Our results suggest that $\mathrm{T} 102 \mathrm{C}$ polymorphism of gene $5-\mathrm{HT} 2 \mathrm{~A}$ is associated with mean life span, and thus this gene becomes a possible candidate to the group of adaptive genes to meat consumption proposed by Finch and Stanford (5). Nevertheless, further studies should be conducted in order to clarify the relationship of genetic polymorphisms and mean life span.

One limitation of the present study is related to the stratification of the population; however, an analysis made by Wacholder et al. (38) suggests that the error attributed to the stratification of a population is minimal. Another limitation is the fact that the population of the present study could be of mixed origin. We are not aware of any published study on the genic frequency of T102C polymorphism of gene 5-HT2A in different ethnic populations. It is possible that ethnically mixed populations like the Brazilian population could cause bias in the genic frequencies observed. We used only a Caucasian sample from Rio Grande do Sul. Genetic studies by Marrero et al. (39) using seven $\gamma$-chromosome polymorphisms comparing 5 subjects classified as white from Veranópolis, a city with a large Italian descendant community, and other samples from different localities of Rio Grande do Sul showed differences in ethnic contribution. In the Veranópolis sample, almost all subjects presented European ancestry. This result was not the same in the second sample that included subjects identified as White that presented significant fractions of Native American (36\%) and African (16\%) mtDNA haplogroups. These results indicate that Brazilian populations are remarkably heterogenous (39). However, we used a Caucasian sample in the genetic analysis and found Hardy-Weinberg equilibrium; thus, we believe that the results obtained here did not present a bias in the ethnic sample selection.

Mean life span is a complex phenomenon that involves many genetic and environmental factors. Colhoun et al. (40) state that the inability to replicate many results has led to continuous skepticism as to the value of the findings of studies of the simple association between a genetic variant and a complex phenotype, as is the case of mean life span. They go on suggesting that one of the most important factors that lies behind this inability to reproduce these associations is publication bias, which fails to attribute result alterations and inadequate sample sizes.

Finally, we believe that the merit of the present study is mainly an attempt to contribute to the understanding of the genetic influence on human life expectation. Our results demonstrated that T102C polymorphism of gene $5-\mathrm{HT} 2 \mathrm{~A}$ was associated with the mean life span. Further studies should be carried out in order to strengthen this suggestion.

\section{Acknowledgments}

We are very thankful to all members of the Programa Gênesis de Pesquisa for having collaborated with us in the data collection and molecular analysis.

\section{References}

1. Martin GM, Bergman A, Barzilai N. Genetic determinants of human health span and life span: progress and new opportunities. PLoS Genet 2007; 3: e125.

2. Browner WS, Kahn AJ, Ziv E, Reiner AP, Oshima J, Cawthon RM, et al. The genetics of human longevity. $A m \mathrm{~J}$ Med 2004; 117: 851-860.

3. Toupance B, Godelle B, Gouyon PH, Schachter F. A model for antagonistic pleiotropic gene action for mortality and advanced age. Am J Hum Genet 1998; 62: 1525-1534.

4. Mitchell BD, Hsueh WC, King TM, Pollin TI, Sorkin J, Agarwala R, et al. Heritability of life span in the Old Order Amish. Am J Med Genet 2001; 102: 346-352.

5. Finch CE, Stanford CB. Meat-adaptive genes and the evolution of slower aging in humans. Q Rev Biol 2004; 79: 3-50.

6. Prado-Lima PS, Cruz IB, Schwanke CH, Netto CA, Licinio J. Human food preferences are associated with a 5-HT(2A) serotonergic receptor polymorphism. Mol Psychiatry 2006; 11: 889-891.

7. Herbeth B, Aubry E, Fumeron F, Aubert R, Cailotto F, Siest $\mathrm{G}$, et al. Polymorphism of the 5-HT2A receptor gene and food intakes in children and adolescents: the Stanislas Family Study. Am J Clin Nutr 2005; 82: 467-470.

8. Veenstra-VanderWeele J, Kim SJ, Lord C, Courchesne R, Akshoomoff N, Leventhal BL, et al. Transmission disequilibrium studies of the serotonin 5-HT2A receptor gene (HTR2A) in autism. Am J Med Genet 2002; 114: 277-283.

9. Anguelova M, Benkelfat C, Turecki G. A systematic review of association studies investigating genes coding for serotonin receptors and the serotonin transporter: II. Suicidal behavior. Mol Psychiatry 2003; 8: 646-653.

10. Vaquero Lorenzo C, Baca-Garcia E, Diaz-Hernandez M, Botillo-Martin C, Perez-Rodriguez MM, Fernandez-Ramos $\mathrm{C}$, et al. Association between the T102C polymorphism of the serotonin-2A receptor gene and schizophrenia. Prog Neuropsychopharmacol Biol Psychiatry 2006; 30: 11361138.

11. do Prado-Lima PA, Chatkin JM, Taufer M, Oliveira G, Silveira E, Neto CA, et al. Polymorphism of 5HT2A serotonin receptor gene is implicated in smoking addiction. $A m \mathrm{~J}$ Med Genet B Neuropsychiatr Genet 2004; 128B: 90-93. 
12. Yamada S, Akita H, Kanazawa K, Ishida T, Hirata K, Ito K, et al. T102C polymorphism of the serotonin (5-HT) 2A receptor gene in patients with non-fatal acute myocardial infarction. Atherosclerosis 2000; 150: 143-148.

13. Olesen OF, Bennike B, Dam H, Mellerup E. Association of the 5-HT2A receptor gene polymorphism 102T/C with ischemic stroke. J Mol Neurosci 2006; 30: 323-328.

14. Yamamoto M, Jin JJ, Wu Z, Abe M, Tabara Y, Nagai T, et al. Interaction between serotonin $2 A$ receptor and endothelin-1 variants in association with hypertension in Japanese. Hypertens Res 2006; 29: 227-232.

15. Ozdener F, Gulbas Z, Erol K, Ozdemir V. 5-Hydroxytryptamine-2A receptor gene (HTR 2 A) candidate polymorphism ( $\mathrm{T} 102 \mathrm{C}$ ): Role for human platelet function under pharmacological challenge ex vivo. Methods Find Exp Clin Pharmacol 2005; 27: 395-400.

16. Little J, Bradley L, Bray MS, Clyne M, Dorman J, Ellsworth $\mathrm{DL}$, et al. Reporting, appraising, and integrating data on genotype prevalence and gene-disease associations. Am J Epidemiol 2002; 156: 300-310.

17. Alves-Silva J, da Silva Santos M, Guimaraes PE, Ferreira AC, Bandelt HJ, Pena SD, et al. The ancestry of Brazilian mtDNA lineages. Am J Hum Genet 2000; 67: 444-461.

18. Parra FC, Amado RC, Lambertucci JR, Rocha J, Antunes CM, Pena SD. Color and genomic ancestry in Brazilians. Proc Natl Acad Sci U S A 2003; 100: 177-182.

19. Da Cruz I, Oliveira G, Taufer M, Leal NF, Schwanke $\mathrm{CH}$, Glock L, et al. Angiotensin l-converting enzyme gene polymorphism in two ethnic groups living in Brazil's southern region: association with age. J Gerontol A Biol Sci Med Sci 2003; 58: M851-M856.

20. Warren JT Jr, Peacock ML, Rodriguez LC, Fink JK. An Mspl polymorphism in the hyman serotonin receptor gene (HTR2): detection by DGGE and RFLP analysis. Hum Mol Genet 1993; 2: 338.

21. Tsai SJ, Hong CJ, Hsu CC, Cheng CY, Liao WY, Song HL, et al. Serotonin-2A receptor polymorphism (102T/C) in mood disorders. Psychiatry Res 1999; 87: 233-237.

22. Aghajanian GK, Sanders-Bush E. Serotonin. In: Davis KL, Charney D, Coyle JT, Nemeroff C (Editors), Neuropsychopharmacology - The Fifth Generation of Progress. New York: Lippincott Williams \& Wilkins; 2002. p 15-25.

23. Jacobs BL, Fornal CA. Serotonin and behavior: a general hypothesis. In: Bloom FE, Kupfer DJ (Editors), Psychopharmacology: The Fourth Generation of Progress. New York: Raven Press; 1995. p 461-469.

24. Bjork JM, Moeller FG, Dougherty DM, Swann AC, Machado MA, Hanis CL. Serotonin 2a receptor T102C polymorphism and impaired impulse control. Am J Med Genet 2002; 114 : 336-339.

25. Li J, Wang Y, Qian Q, Wang B, Zhou R. Association of 5$\mathrm{HT}(2 \mathrm{~A})$ receptor polymorphism and attention deficit hyperactivity disorder in children. Zhonghua Yi Xue Za Zhi 2002; 82: 1173-1176.

26. Choi JH, Zhang SY, Park KW, Cho YS, Oh BH, Lee MM, et al. The association between the T102C polymorphism of the HTR2A serotonin receptor gene and HDL cholesterol level in Koreans. J Biochem Mol Biol 2005; 38: 238-242.

27. Liolitsa D, Powell JF, Prince M, Lovestone S. Association study of the $5-\mathrm{HT}(2 \mathrm{~A})$ receptor gene polymorphism, T102C and essential hypertension. J Hum Hypertens 2001; 15 : 335-339.

28. Roth BL, Meltzer HY. The role of serotonin in schizophrenia. In: Nemeroff CB, Kupfer D (Editors), Psychopharmacology: The Fourth Generation of Progress. New York: Raven Press; 1995. p 1215-1227.

29. Kendler KS, Diehl SR. The genetics of schizophrenia: a current, genetic-epidemiologic perspective. Schizophr Bull 1993; 19: 261-285.

30. Williams J, Spurlock G, McGuffin P, Mallet J, Nothen MM, Gill M, et al. Association between schizophrenia and T102C polymorphism of the 5-hydroxytryptamine type 2a-receptor gene. European Multicentre Association Study of Schizophrenia (EMASS) Group. Lancet 1996; 347: 1294-1296.

31. Williams J, McGuffin P, Nothen M, Owen MJ. Meta-analysis of association between the 5-HT2a receptor T102C polymorphism and schizophrenia. EMASS Collaborative Group. European Multicentre Association Study of Schizophrenia. Lancet 1997; 349: 1221.

32. Abdolmaleky HM, Faraone SV, Glatt SJ, Tsuang MT. Metaanalysis of association between the T102C polymorphism of the $5 \mathrm{HT} 2 \mathrm{a}$ receptor gene and schizophrenia. Schizophr Res 2004; 67: 53-62.

33. Meneghel SN, Victora CG, Faria NM, Carvalho LA, Falk JW. Epidemiological aspects of suicide in Rio Grande do Sul, Brazil. Rev Saúde Pública 2004; 38: 804-810.

34. Sheline YI, Mintun MA, Moerlein SM, Snyder AZ. Greater loss of $5-\mathrm{HT}(2 \mathrm{~A})$ receptors in midlife than in late life. $\mathrm{Am} \mathrm{J}$ Psychiatry 2002; 159: 430-435.

35. Polesskaya OO, Sokolov BP. Differential expression of the "C" and "T" alleles of the 5-HT2A receptor gene in the temporal cortex of normal individuals and schizophrenics. $J$ Neurosci Res 2002; 67: 812-822.

36. Gondo Y, Hirose N, Arai Y, Yamamura K, Shimizu K, Takayama $\mathrm{M}$, et al. Contribution of an affect-associated gene to human longevity: prevalence of the long-allele genotype of the serotonin transporter-linked gene in Japanese centenarians. Mech Ageing Dev 2005; 126: 1178-1184.

37. Stessman J, Maaravi Y, Hammerman-Rozenberg R, Cohen A, Nemanov L, Gritsenko I, et al. Candidate genes associated with ageing and life expectancy in the Jerusalem longitudinal study. Mech Ageing Dev 2005; 126: 333-339.

38. Wacholder S, Rothman N, Caporaso N. Population stratification in epidemiologic studies of common genetic variants and cancer: quantification of bias. J Natl Cancer Inst 2000; 92: 1151-1158.

39. Marrero AR, Das Neves Leite FP, De Almeida Carvalho B, Peres LM, Kommers TC, Da Cruz I, et al. Heterogeneity of the genome ancestry of individuals classified as White in the State of Rio Grande do Sul, Brazil. Am J Hum Biol 2005; 17: 496-506.

40. Colhoun HM, McKeigue PM, Davey SG. Problems of reporting genetic associations with complex outcomes. Lancet 2003; 361: 865-872. 